\title{
IDENTIFIKASI SAKARIN PADA KUE BURONCONG YANG DIJUAL DI KECAMATAN PANAKKUKANG KOTA MAKASSAR
}

\author{
Muhammad Nasir ${ }^{1}$, Faisal Idris ${ }^{2}$ \\ ${ }^{1,2}$ Jurusan Analis Kesehatan Poltekkes Kemenkes Makassar
}

Koresponden : nasir@poltekkes-mks.ac.id

\begin{abstract}
ABSTRAK
Penelitian ini dilatarbelakangi oleh banyaknya produsen makanan yang masih menggunakan bahan tambahan makanan seperti sakarin. Tujuan penelitian ini untuk mengetahui adanya sakarin pada kue buroncong yang dijual di Kecamatan Panakkukang Kota Makassar. Sakarin merupakan golongan bahan tambahan makanan yang diizinkan oleh Permenkes RI no.722/Menkes/Per/IX/88 untuk digunakan dalam makanan, namun apabila dikonsumsi secara berlebihan dapat menyebabkan dampak yang berbahaya bagi kesehatan manusia diantaranya tumor pada otak, multiple sklerosis, epilepsi, sindrom kelelahan kronis, parkinson, lupus, alzheimer, cacat mental, limfoma, kelainan pada kelahiran anak, dan bahkan diabetes. Jenis penelitian ini bersifat observasi laboratorik. Sampel yang digunakansebanyak 5 sampel dan teknik pengambilan sampel secara random sampling. Penelitian ini telah dilakukan pada tanggal 27-28 juli 2016 di Laboratorium Kimia Jurusan Analis Kesehatan Politeknik Kesehatan Kemenkes Makassar.Dari hasil penelitian yang telah dilakukan dan dapat disimpulkan bahwa semua sampel yang telah diperiksa tidak mengandung sakarin.
\end{abstract}

Kata Kunci : Sakarin dan Buroncong

\section{PENDAHULUAN}

Berdasarkan definisi dari World Health Organization, makanan adalah semua substansi yang di butuhkan oleh tubuh tidak termaksud air, obat-obatan dan substansisubstansi lain yang digunakan untuk pengobatan. Makanan merupakan salah satu bagian yang penting untuk kesehatan manusia mengingat setiap saat dapat saja terjadi penyakitpenyakit yang diakibatkan oleh makanan. (Chandra, Budiman, 2007).

Dengan semakin berkembangnya ilmu dan teknologi makanan, semakin banyak intervensi manusia dalam pembentukan atau pengolahan bahan makanan yang mendorong penambahan bahan-bahan lain kedalam makanan. Bahan-bahan yang ditambahkan tersebut dapat berasal dari bahan alami yang dipisahkan dan dimurnikan ataupun hasil buatan secara kimiawi atau sintetis. Tujuan dari penambahan bahan-bahan makanan tersebut, yaitu sebagai pengawet, pengering dan sebagai pemanis buatan (Sinaga, 1993 dalam Marga, 2003).

Pemanis merupakan senyawa kimia yang sering ditambahkan dan digunakan untuk keperluan produk olahan pangan, industri, serta minuman dan makanan kesehatan. Pemanis berfungsi untuk meningkatkan cita rasa dan aroma, 
memperbaiki sifat-sifat fisik, sebagai pengawet, memperbaiki sifat-sifat kimia sekaligus merupakan sumber kalori bagi tubuh, mengembangkan jenis minuman dan penurunan berat badan, mengurangi kerusakan gigi, dan sebagai bahan substitusi pemanis utama (Eriawan R. Dan Iman P, 2002).

Perkembangan industri pangan dan minuman akan kebutuhan pemanis dari tahun ke tahun semakin meningkat. Industri pangan dan minuman lebih menyukai menggunakan pemanis sintetis karena selain harganya relatif murah, tingkat kemanisan pemanis sintetis jauh lebih tinggi (10 - 300x lebih manis) dari pemanis alami. (Cahyadi, 2008)

Diantara berbagai jenis pemanis buatan atau sintetis, hanya beberapa saja yang diizinkan penggunaannya dalam makanan sesuai Peraturan Menteri Kesehatan RI Nomor 208/Menkes/Per/IV/1985, di antaranya sakarin, siklamat dan aspartam.

Menurut peraturan Menteri Kesehatan Republik Indonesia Nomor 722/Menkes/Per/IX/1988 tentang bahan tambahan pangan,

\section{METODE}

Desain, tempat dan waktu

Jenis peneitian ini merupakan penelitian observasi laboratorik Lokasi penelitian telah dilaksanakan di Laboratorium Kimia Jurusan Analis Kesehatan, Politeknik Kesehatan Kementerian Kesehatan Makassar pada tanggal 27-28 juli 2016

Sampel dalam penelitian ini adalah kue buroncong yang diambil dari 5 penjual yang berada di Kecamatan Panakkukang Kota bahwa sakarin dapat diberikan dalam pangan olahan khusus berkalori rendah dan untuk penderita diabetes mellitus dengan kadar maksimal 300 $\mathrm{mg} / \mathrm{kg} \quad$ BB. Adapun jumlah maksimum yang dapat dikonsumsi per hari ialah 0-2,5 mg/kg BB.

Kue buroncong khas Makassar adalah salah satu kue yang hingga kini masih diminati. Bentuknya mirip dengan pukis yang berbentuk setengah lingkaran. Kue ini terbuat dari tepung terigu yang dicampur dengan parutan kelapa muda, soda kue, gula dan juga santan.Cara membuat kue buroncong ini adalah dengan memanggangnya dalam

cetakan di atas baraapi yang berasal dari kayu bakar. Pada proses pembuatan kueburoncong terkadang para produsen sering menggantikan gula alami dengan pemanis buatan, yang bila ditinjau dari segi kemanisan dan harganya sangat menguntungkan.

Berdasarkan uraian tersebut maka penulis telah melakukan penelitian tentang identifikasi sakarin pada kue buroncong yang dijual di Kecamatan Panakkukang Kota Makassar.

Makassar. Dengan Teknik Pengambilan Sampel menggunakan metode Random Sampling.

Alat dan Bahan Penelitian

Alat dan bahan yang akan digunakan dalam penelitian, yaitu : Alat Blender, timbangan analitik, gelas arloji, sendok tanduk, beaker gelas, gelas ukur, batang pengaduk, pipet tetes, pipet ukur, pipet volume, pom karet, kertas lakmus, erlenmeyer, corong, labu ukur, aluminium foil, corong pemisah, cawan porselin, tabung reaksi, 
penjepit tabung, rak tabung, dan lampu spiritus. Sedangkan bahan yaitu: Sampel (kue buroncong), aquadest, eter, $\mathrm{HCl} 10 \%, \mathrm{HCl} 25 \%$, $\mathrm{H}_{2} \mathrm{SO}_{4}$ pekat, $\mathrm{NH}_{4} \mathrm{OH} 5 \%$, resorsinol dan $\mathrm{NaOH} 10 \%$.

Prosedur Penelitian

Analisis kualitatif Sakarin dengan Uji Resorsinol (dengan sampel berlemak)

1. Prinsip

Sakarin akan memberikan warna hijau flouresensi jika direaksikan dengan resorsinol dan $\mathrm{NaOH}$ berlebihan.

\section{Cara Kerja}

Sampel dihaluskan, kemudian ditimbang sebanyak 25 gram dimasukkan kedalam beaker gelas, larutkan dengan aquades $75 \mathrm{ml}$ kemudian di saring. Sampel diasamkan dengan $\mathrm{HCl} 10 \%$ lalu diekstraksi dengan $25 \mathrm{ml}$ eter. Ekstrak eter dicuci 2 kali masingmasing dengan $10 \mathrm{ml}$ amonium hidroksida $\left(\mathrm{NH}_{4} \mathrm{OH}\right) \quad 5 \%$ lalu dipisahkan. Lapisan $\mathrm{NH}_{4} \mathrm{OH}$ ditambah dengan $10 \mathrm{ml} \mathrm{HCl} \mathrm{25 \%}$ lalu diekstraksi 3 kali masingmasing dengan $25 \mathrm{ml}$ eter. Lapisan eter dikumpulkan dan dicuci dengan akuades hingga netral lalu diuapkan di udara terbuka. Residu ditambah dengan 10 tetes $\mathrm{H}_{2} \mathrm{SO}_{4}$ pekat lalu dipindahkan kedalam tabung reaksi, ditambah dengan 40 mg resorsinol, dan dipanaskan secara perlahan-lahan dengan nyala api kecil sampai berubah menjadi warna hijau kotor. Tabung reaksi didinginkan lalu ditambah dengan $10 \mathrm{ml}$ akuadest dan larutan $\mathrm{NaOH} 10 \%$ berlebihan. Bila terbentuk warna hijau flouresensi berarti menunjukan adanya sakarin.

Analisa Data hasil penelitian disajikan secara deskriptif dengan menggunakan tabel dan hasilnya dibahas dalam bentuk narasi.

\section{HASIL}

Dari hasil identifikasi sakarin pada kue buroncong yang dijual di Kecamatan Panakkukang Kota Makassar, menggunakan sampel kue buroncong sebanyak 5 dari penjual yang berbeda, dilakukan secara random sampling dan diperiksa menggunakan metode uji Resorsinol, maka didapatkan hasil sebagai berikut

Tabel 4.1 Hasil identifikasi sakarin pada kue buroncong yang dijual Kecamatan Panakkukang Kota Makassar

\begin{tabular}{ccc}
\hline NO. & $\begin{array}{c}\text { Kode } \\
\text { Sampel }\end{array}$ & $\begin{array}{c}\text { Hasil } \\
\text { Pemeriksaaan }\end{array}$ \\
\hline $\mathbf{1 .}$ & $\mathrm{A}$ & Negatif \\
\hline $\mathbf{2 .}$ & $\mathrm{B}$ & Negatif \\
\hline $\mathbf{3 .}$ & $\mathrm{C}$ & Negatif \\
\hline $\mathbf{4 .}$ & $\mathrm{D}$ & Negatif \\
\hline $\mathbf{5 .}$ & $\mathrm{E}$ & Negatif \\
\multicolumn{3}{l}{ Sumber : data primer Juli 2016$)$}
\end{tabular}

Berdasarkan penelitian buroncong sebanyak 5 dari penjual identifikasi sakarin pada sampel kue berbeda yang dijual di Kecamatan 
Panakkukang Kota Makassar maka didapatkan hasil semua sampel tidak mengandung sakarin.

\section{PEMBAHASAN}

Penelitian yang dilakukan merupakan penelitian yang bersifat observasi laboratorik yang bertujuan untuk mengetahui adanya sakarin pada kue buroncong yang dijual di Kecamatan Panakkukang Kota Makassar.

Dalam identifikasi sakarin ini sampel yang digunakan adalah kue buroncong sebanyak 5 dari penjual berbeda yang dijual di Kecamatan Panakkukang Kota Makassar, sampel tersebut di uji secara kualitatif dengan resorsinol.

Dalam penelitian ini prosedur yang digunakan ialah ekstraksi. Sebelum dilakukan ekstraksi terlebih dahulu sampel kue buroncong dihaluskan dan disaring kemudian diasamkan dengan $\mathrm{HCl} 10 \%$. Fungsi pengasaman tersebut adalah agar sakarin yang terdapat dalam sampel mengalami hidrolisa menjadi asam $\mathrm{O}$ Sulfamoil-Benzoat, atau dalam suasana asam akan menjadi asam amonium O-Sulfo-Benzoat. Ekstraksi merupakan proses pemisahan suatu zat berdasarkan perbedaan kelarutannya terhadap dua cairan tidak saling larut yang berbeda, biasanya air dan yang lainnya pelarut organik. Atau dengan istilah lain ekstraksi merupakan proses pemisahan komponen berdasarkan dua fasecair yang berbeda.

Larutan yang diekstraksi pada penelitian ini ialah kue buroncong yang telah dihaluskan dan larutan eter. Eter digunakan sebagai pelarut karena merupakan salah satu pelarut organik yang tidak bisa bercampur dengan air.

Sakarin akan larut dalam eter dan menyatu dalam lapisan eter. Kemudian ekstrat dicuci dengan aquadest dan diuapkan sehingga eter yang ada pada sampel menguap (hilang) yang ditandai dengan hilangnya bau yang menyengat. Eter akan mudah menguap dan hilang dikarenakan memiliki titik didih yang sangat rendah. Setelah eter menguap, tersisa residu pada beaker gelasyang kemudian ditambahkan 10 tetes $\mathrm{H}_{2} \mathrm{SO}_{4}$ pekat untuk memecahkan garam pada sakarin, kemudian dipindahkan kedalam tabung reaksi. Pembacaan perubahan warna dilakukan dengan melihat dari atas tabung. Ditambahkan dengan $40 \mathrm{mg}$ resorsinol, dan dipanaskan secara perlahan-lahan dengan nyala api kecil sampai berubah menjadi warna hijau kotor. Tabung reaksi didinginkan lalu ditambah dengan $10 \mathrm{ml}$ aquadest dan larutan $\mathrm{NaOH} 10 \%$ berlebihan. Bila terbentuk warna hijau flouresensi berarti menunjukan adanya sakarin. Pada penelitian ini sampel yang telah diperiksa tidak terbentuk warna hijau flouresensi maka dapat disimpulkan sampel tersebut tidak mengandung sakarin.

\section{KESIMPULAN}

Berdasarkan hasil identifikasi sakarin pada kue buroncong yang dijual di Kecamatan Panakkukang Kota Makassar maka dapat disimpulkan semua sampel tidak mengandung sakarin. 


\section{SARAN}

Berdasarkan penelitian yang telah dilaksanakan maka peneliti menyarankan:

1. Kepada Badan Pengawasan Obat dan Makanan (BPOM) disarankan untuk memberikan informasi dan penjelasan kepada

\section{DAFTAR PUSTAKA}

Analis Kesehatan Poltekkes. 2014.

Pedoman Penulisan KTI Edisi

3. Makassar: Jurusan Analis

Kesehatan Poltekkes.

Cahyadi Wisnu. 2008. Bahan

Tambahan Pangan Edisi Kedua

Cetakan Pertama. Jakarta: PT

Bumi Aksara.

Chandra, Budiman. 2007. Pengantar Kesehatan Lingkungan. Buku Kedokteran EGC. Jakarta.

C. Hanny Wijaya, Noryawati M. 2010. Bahan Tambahan Pangan, Pemanis. Bogor: IPB Press.

Fardiaz D. 2009. Waspada Pemanis

Buatan.

http://melileaku.com/?p=192.

Diakses tanggal 17 Mei 2016.

Effendi, M. Supli. 2012. Teknologi Pengolahan dan Pengawetan Pangan. CV. Alvabeta. Bandung.

Herliani L Afrianti. 2008. Teknologi Pengawetan Pangan. Bandung: Alfabeta.

Irianto Koes. 2014. Ekologi Kesehatan (Health Ecology). Bandung: Alfabeta.

Martoyo, Soemantri, Koesnandar. 1996. Terampil Menguasai dan Menerapkan Konsep Kimia (Edisi Revisi). PT Tiga Serangkai Pustaka Mandiri. masyarakat tentang bahan tambahan makanan (pemanis buatan).

2. Disarankan untuk peneliti selanjutnya bisa melakukan identifikasi sakarin dengan menggunakan metode yang lain pada jenis makanan .

Nuralfiah. 2013. Sakarin. Online. www.kompasiana.com.

Diakses tanggal 06 Mei 2016.

Peraturan Menteri Kesehatan Tahun 1985 Tentang Bahan Tambahan

Pangan (Online) Permenkes\%200331985\%20Ba han\%20 Tambahan \%20 Pangan. pdf. Diakses tanggal 01 Mei 2016.

Rohman Abdul, Sumantri. 2013. Analisis Makanan. Yogyakarta: Gadjah Mada University Press.

Rahman, Dra. Hj. Suryaningsih, Nur Adi. 2012. Analisis Makanan dan Minuman.

Subhan.2013.http://downloadskripsi. pdf.blogspot.com/2013/08/pen ggunaan-sakarin-dan-siklamat pada.html. Diakses tanggal 04 Mei 2016.

Winarno F.G. 1984. Kimia Pangan dan Gizi (Cetakan Pertama). Jakarta: PT Gramedia Pustaka Utama.

Yuliarti Nurheti. 2007. Awas! Bahaya DI Balik Lezatnya Makanan. Yogyakarta: CV ANDI OFF 